\title{
As práticas corporais femininas em clubes paulistas do início do século XX
}

CDD. 20.ed.
Milena Bushatsky MATHIAS*
Kátia RUBIO*
*Escola de Educação Física e Esporte, Universidade de São Paulo.

\section{Resumo}

Na década de 20, o esporte ainda era visto como uma instituição masculina, o que invalidava a experiência atlética feminina, sendo apenas o atletismo, a dança clássica e o bola ao cesto, consideradas atividades saudáveis para o intitulado "sexo frágil". Uma vez excluídas dos estádios e instituições esportivas, assim como da própria vida pública determinada na época, a condição feminina foi limitada pela dedicação ao lar e à família.Em contrapartida, o Movimento Feminista lutava pelo direito à cidadania, à uma existência legal na vida pública e a própria Educação Física apontava através de seus discursos a mulher como fisicamente ativa, dentro de propósitos eugenistas e higienistas. 0 objetivo deste trabalho é discutir como se deu a participação da mulher nas práticas corporais em clubes na década de 20 na cidade de São Paulo.

Unitermos: Feminismo; Clubes; Esporte; Mulher; Década de 20.

\section{Introdução}

O século XX representou um importante marco para o movimento feminista porque ao longo dele pode-se observar a transformação de discursos e práticas sobre a condição feminina. Entretanto, nas primeiras décadas do século passado a mulher era viveram parcialmente sua condição de sujeito histórico, em função da cristalização de comportamentos e da rigidez dos papéis sociais. Naquele momento o comportamento feminino era observado dentro de um ideal que alocava a mulher no "recôndito do lar", restringindo suas ações ao tripé "mãe-esposa-dona de casa".

Essa condição ganhou amparo legal com o código civil de 1916, o qual subordinava a mulher ao homem, legalizando uma dependência e subordinação que já era defendida com argumentos biológicos. Dessa forma, restava à mulher desempenhar atividades da esfera da vida privada, sendo atribuídas a ela as funções de casar, gerar filhos para a pátria e plasmar o caráter dos cidadãos de amanhã. Diante disso, não restava realização possível para as mulheres fora do lar; nem para os homens dentro de casa, já que a eles pertencia a rua e o mundo do trabalho (MALuF \& Мотт, 1998). E assim firmava-se a oposição entre as esferas pública e privada, definindo os papéis sociais, de acordo com as expectativas e imposições sociais.
Nesse mesmo período o Movimento Feminista viveu um momento de intensa organização e atuação, ainda que fragmentado e dependente de esforços individuais, ganhou visibilidade em defesa dos direitos da mulher. Entre suas bandeiras de luta estavam o direito ao voto, à educação e o acesso ao mercado de trabalho.

Diante da complexidade do tema Freedman (2004) afirma que diante da diversidade de seu objeto de estudo, das correntes de pensamento acerca do tema e das estratégias de ação talvez fosse mais adequado utilizar o conceito de feminismos no plural. Isso porque somente seria possível apontar uma base comum a todas essas diferentes correntes dentro do feminismo se o foco for a situação de inferioridade que sofrem as mulheres na sociedade e da discriminação que encontram em função de seu sexo e a exigência de transformações sociais, econômicas, políticas e culturais para reduzir e superar essa discriminação.

Entendendo que as práticas corporais de movimento acompanham a dinâmica social, este trabalho tem como objetivo investigar o processo de inclusão das mulheres em diversas práticas corporais na cidade de São Paulo durante a década de 20. Esse recorte histórico justifica-se pela importância que esse período de atuação do Movimento Feminista no Brasil teve 
para as conquistas das mulheres ao longo do século XX. Para tanto foram tomadas como fontes primárias relacionadas à participação das mulheres em práticas corporais periódicos, fotos, jornais e documentos de época, consultados, "in loco", nos centros pró-memória do Clube Esperia, do Esporte Clube Pinheiros e do Clube Atlético Paulistano. De todo o material coletado foram selecionados os artigos informativos ou descritivos que se referem especificamente a participação feminina nas prática esportivas.

O referencial teórico utilizado para análise do material é da epistemologia feminista, que entende as mulheres como sujeitos sociais e políticos, e também como sujeitos do conhecimento.

Isso porque KolNes (1995) afirma que criamos nosso gênero tendo como referência as normas da heterossexualidade e sua organização, sendo a primeira o produto bem sucedido da socialização de gênero. E prossegue dizendo que com algumas exceçôes a heterossexualidade não tem sido problematizada como um princípio organizador na literatura sobre gênero e esporte. Isso é surpreendente na medida que o corpo é um importante símbolo de sexualidade e que o esporte é uma instituição social que busca focar o físico.

\section{Um novo século uma nova mulher}

O final do império, final da escravidão e início da república representaram um importante cenário para o início do século XX. As perspectivas de reestruturação das relações de trabalho em novas bases, a transição do sistema econômico agrário para o fabril, a ampliação e a complexificação dos espaços urbanos, o aumento significativo da imigração, entre outros aspectos, sinalizavam o advento de um novo tempo. Também eram formuladas e executadas novas estratégias de disciplinarização e de representação dos corpos e mentes, que correspondiam às expectativas e interesses dominantes e apontavam para uma nova ética do trabalho e novos padróes de moralidade para os comportamentos afetivos, sexuais e sociais.

A ciência despontava como paradigma e a medicina social oferecia as justificativas para a determinação de papéis e espaços sociais femininos e masculinos. Por razões biológicas, eram asseguradas como características das mulheres a fragilidade, o recato, o predomínio das faculdades afetivas sobre as intelectuais e a subordinação da sexualidade à vocação maternal. A gestação e a maternidade eram as justificativas para esses cuidados. Essas características eram suficientes para justificar que se exigisse das mulheres uma atitude de submissão, um comportamento que não maculasse sua honra. Estavam impedidas do exercício da sexualidade antes de se casarem e, depois, deviam restringi-la ao âmbito desse casamento. As mulheres, segundo ENGEL (1997), dotadas de intenso erotismo e forte inteligência seriam despidas do sentimento de maternidade, característica inata da mulher normal, e deveriam ser afastadas do convívio social.

Por outro lado a situação do homem justificava-se com argumentos que congregavam sua força física a uma natureza autoritária, empreendedora, racional e uma sexualidade exacerbada.

A imagem idealizada de mulher, possível para as elites urbanas, também foi exigida das camadas populares, muito embora a condição econômica não favorecesse essa identificação, uma vez que a inserção das mulheres no mercado de trabalho era necessária tanto para suprir as demandas da industrialização e como à complementação da renda familiar.

No início da industrialização brasileira era significativo o número de mulheres e crianças nas fábricas, principalmente de fiação e tecelagem, representando a maioria da força de trabalho, por ser abundante e barata (RAGO, 1997). Colaborou para essa situação o as demandas geradas pela Primeira Guerra Mundial, como o afastamento dos homens da vida produtiva e a necessidade de produção de suprimentos de todas as ordens. Após esse período, as mulheres foram progressivamente expulsas das fábricas, na medida em que avançavam a industrialização e a re-incorporação da força de trabalho masculina.

A variação salarial, passando pela intimidação física, à desqualificação intelectual ao assédio sexual, eram apenas algumas das barreiras enfrentadas pelas mulheres para participar do mundo dos negócios. Destaca-se, nesse contexto, a frequente associação entre a mulher no trabalho e a questão da moralidade. "Nas denúncias dos operários militantes, dos médicos higienistas, dos juristas, dos jornalistas, a fábrica é descrita como 'antro da perdição', 'bordel' ou 'lupanar', enquanto a trabalhadora é vista como uma figura totalmente passiva e indefesa" (RAGO, 1997 , p.585). Essa visão estava associada, direta ou indiretamente, à intenção de direcionar a mulher à esfera da vida privada. 
Diante das necessidades impostas pelo contexto histórico a sociedade passou a divulgar a necessidade de uma nova esposa, mais moderna, mais consciente, menos subjugada à tirania do marido, mas nem por isso menos dedicada ao lar e à família. "A maternidade ganha ares de profissão, baseada em habilidades altamente qualificadas e especializadas e se torna o valor central das mulheres das famílias de classe média e alta" (BRusChinI, 1990, p.66).

Na segunda metade do século XIX e nas primeiras décadas do século XX, as lutas e manifestações esparsas do movimento pelo direito das mulheres cederam lugar a uma campanha mais orgânica pelos direitos políticos de votarem e de serem votadas. O movimento sufragista espalhou-se pela Europa e pelos Estados Unidos, construindo a primeira vaga de feminismo organizado no mundo (PINTO, 2003, p.13).

Os movimentos europeus e norte-americanos exerceram uma grande influência sobre as mulheres latinoamericanas. No Brasil, a primeira fase do feminismo, que abrangeu o final do século XIX e as três primeiras décadas do século XX, esteve intimamente associada a personalidades. Mesmo quando apresentou algum grau de organização, essa derivava do esforço pessoal de alguma mulher, que por sua excepcionalidade, na maioria das vezes intelectual, rompia com os papéis para ela estabelecidos e se colocava no mundo público em defesa dos direitos femininos.

Nesse período é possível identificar três vertentes distintas no movimento feminista. A primeira, mais forte e organizada, tinha como foco a luta das mulheres pelos direitos políticos, mediante a participação eleitoral. Essa luta esteve associada ao nome de Bertha Lutz, que exerceu inegável liderança durante a década de 20. Ela acreditava que o acesso aos direitos políticos era essencial à obtenção de garantias com base na lei. Em 1922, ela instalou a Federação Brasileira para o Progresso Feminino (FBPF), vinculando o feminismo brasileiro ao norte-americano, no caso a National American Woman's Suffrage Association. Por meio da FBPF, buscava o reconhecimento dos direitos da mulher e sua ampla participação na vida pública (SOIHET, 2002). Esse feminismo, porém, não definia a posição de exclusão da mulher como decorrência da posição de poder do homem, de forma que a luta pela inclusão não se apresentava como alteração das relaçōes de gênero.

A segunda vertente caracterizava-se por um feminismo difuso, que se expressava nas múltiplas manifestações da imprensa feminista alternativa. Eram, na grande maioria, professoras, escritoras e jornalistas que discutiam um campo mais vasto de questôes; defendiam a educação da mulher e falavam sobre a dominação dos homens e seus interesses em deixá-las fora do mundo público. $\mathrm{O}$ discurso enfatizava a dificuldade do ingresso no mundo do trabalho, pois, mesmo tendo vencido o primeiro desafio de se formarem como médicas, engenheiras, advogadas, entre outras profissões liberais, as mulheres ainda encontravam muitos obstáculos para firmarem-se profissionalmente (RAGO, 1997).

A terceira vertente se baseava no movimento anarquista e, posteriormente, no Partido Comunista. Eram militantes dos movimentos de esquerda que defendiam a libertação da mulher de uma forma radical, articulando as teses feministas aos ideários anarquistas e comunistas. As anarquistas procuravam mostrar como a questão da emancipação da mulher poderia ser encaminhada e resolvida por intermédio da "revolução social" mais ampla, que daria origem a um mundo fundado na igualdade, na justiça e na liberdade. A luta pela libertação feminina estava subordinada à ideia de emancipação de toda a humanidade, pois elas "consideravam a questão feminina secundária em relação ao conflito de classes sociais, cuja resolução, consequentemente, acabaria com o problema da opressão sexual. No entanto, em sua luta cotidiana, as operárias anarquistas procuravam colocar o debate na ordem do dia, questionando não apenas o patriarcalismo da sociedade brasileira, mas a discriminação sexual no meio operário e no ambiente de militância política" (RAGO, 1997, p.597).

Maria Lacerda de Moura, uma anarquista e feminista de classe média, professora, escritora e ativista política radical, foi, em sua época, uma das raras pontes entre o mundo operário e o mundo das elites intelectuais e artísticas do país. Em 1920, juntamente com Bertha Lutz, ela fundou no Rio de Janeiro a Liga para a Emancipação Internacional da Mulher, um grupo de estudos cuja preocupação principal era lutar pela igualdade política das mulheres. Por suas preocupaçôes transcenderem a luta pelo direito ao voto, ela fundou, em 1921, a Federação Internacional Feminina, que objetivava "canalizar todas as energias femininas dispersas, no sentido da cultura filosófica, sociológica, psicológica, ética, estética - para o advento da sociedade melhor" (RAGO, 1997, p.600). Maria Lacerda também publicou, em 1923, a revista $A$ Renascença e fez inúmeras palestras nos meios intelectuais e nos círculos operários, nas quais foi uma das poucas mulheres que contestou publicamente as concepçóes médicas a respeito da sexualidade e da constituição física feminina. 


\section{As práticas corporais e o feminino}

O comportamento no âmbito das práticas corporais não se encontra isolado da dinâmica social, mas é reflexo das relações estabelecidas nesse espaço maior. Portanto, a prática de atividades físicas na década de 20 pode ser observada como um microcosmo, dentro do macrocosmo que é a sociedade paulistana do final da Primeira República.

Nesse período, a disseminação das práticas corporais - cada vez mais presentes em clubes e escolas - estava intimamente ligada ao controle corporal, ou seja, às preocupaçôes higiênicas, eugênicas, médicas, morais e disciplinares. Dessa forma, havia uma nítida distinção entre as práticas aconselhadas a mulheres e homens, de forma que a preparação física reforçava as características corporais e comportamentais que distinguiam os sexos, reforçando a construção de gênero.

A compreensão do conceito de gênero refere-se à organização social entre os sexos. Conforme SCOTT (1999) essa palavra busca indicar uma rejeição ao determinismo biológico implícito no uso de termos como sexo ou diferença sexual, destacando o aspecto relacional das construçōes conceituais sobre o feminino, deslocando-o de uma condição apenas anatômica e funcional.

Essas práticas discursivas podem ser entendidas no bojo do conceito de linguagem relacionada com a construção e circulação do significado, conforme GUARESCHI, Medeiros e Bruschi (2003). Nesse contexto a linguagem deixa de ser uma forma de relatar ou transmitir com neutralidade os significados que se pretende expressar e passa a constituí-los diretamente. Dessa forma, os considerados fatos naturais, também denominados realidade, são tidos como fenômenos discursivos, cujos significados surgem a partir dos jogos de linguagem e dos sistemas de classificação nos quais estão inseridos. E assim, o discurso não é entendido no seu aspecto linguístico ou como um conjunto de palavras, mas como um conjunto de práticas que produzem efeitos no sujeito.

Nessa perspectiva tudo o que se pensa ou se diz da realidade é um reflexo e uma projeção da experiência vivida como real, independente da afirmação dessa realidade exterior ao sujeito e dos sentidos que são dados a ela. Isso representa a existência de uma materialidade conectada com o que se pensa e se diz, ligada ao discurso. Embora a realidade seja intangível, é sabido que ela existe e que está conectada com a representação que se tem dela (VEIGA-NETo, 2000).

Essas representaçōes se destacam nas discussōes sobre gênero e a naturalização da atividade física, e principalmente a atividade esportiva competitiva.

"Sob a cobertura do 'natural', uma disciplina dos corpos masculinos se impõe: os rapazes parecem ser espontaneamente atraídos pela competição, pelo treinamento físico e pelo desenvolvimento muscular, já que tudo isso só reforça neles a virilidade e, por consequência, a 'natureza' máscula” (SCHPUN, 1999, p.37-8). Assim, esperava-se que os jovens seguissem a atualidade esportiva, participassem dos acontecimentos organizados nos estádios, torcessem por um time de futebol, se preocupassem com sua forma física e, sobretudo, praticassem esportes.

O discurso sobre a prática de atividades físicas por mulheres - que afirmava a inaptidão da constituição física feminina - sofreu transformaçōes no início do século $\mathrm{XX}$. Visando a produção da "nova mulher", que deveria acompanhar os desafios da modernidade, deixava-se de valorizar a debilidade e a indolência feminina, assim como o ócio e a preguiça passaram a conformar o mal da alma e deveriam ser substituídos pela vitalidade do corpo e pela capacidade de resistir às intempéries da vida.

Essa transformação do pensamento da época exigiu uma grande dedicação por parte de alguns intelectuais que buscavam relacionar as benesses físicas e morais da ginástica feminina com o engrandecimento geral da Nação. Dentre eles, Fernando de Azevedo teve um importante papel por sua longa trajetória científicoliterária, na qual destacam-se Da Educação Physica e Antinoüs: estudo de cultura atlhetica, ambos publicados em 1920. Nelas procurou construir uma doutrina pedagógica para a Educação Física brasileira condizente com o prestígio social dos métodos ginásticos europeus*, mais especificamente com os pressupostos higienistas e eugenistas que os fundamentavam (GOELLNER, 2004).

Fernando de Azevedo pensava a Educação Física como uma ação científica, "inserida dentro de um plano nacional de educação, que desenvolveria ao máximo a virilidade, as virtudes da raça e as aptidões hereditárias de cada indivíduo. Uma educação física que, pautada por um estatuto científico e ao mesmo tempo moral, estivesse articulada à medicina e às normas jurídicas em favor de uma nova ordenação dos corpos, constituindo, assim, uma consistente retórica corporal na qual estruturava sua proposta de 'corpo-nação"' (GOELLNER, 2004, p.161). Buscava-se a eliminação da fraqueza orgânica, que além de debilitar cada sujeito por ela atingido, também debilitava a ideia de uma Nação poderosa.

Ainda que fossem várias as restriçôes impostas e os cuidados a serem seguidos, Fernando de Azevedo atribuía grande importância aos exercícios corporais femininos para a formação das "obreiras da vida". Essa concepção apontava a maternidade como a mais nobre missão da mulher, pois dela dependia a regeneração da sociedade. 
Dessa forma, o cuidado e a preservação do corpo-saúde das "obreiras da vida" estava diretamente relacionado à manutenção do corpo-saúde da própria Nação.

Ainda assim, a aceitação de mulheres em esportes e outras atividades físicas vivia a dualidade entre as propostas eugenistas e higienistas, e certas características comuns ao universo da cultura física - como o suor excessivo, o esforço físico, as emoçôes fortes, as competições, a rivalidade consentida, os músculos delineados, os perigos das lesões e a leveza das roupas - que, quando relacionados à mulher, despertavam suspeitas por parecerem abrandar certos limites que contornavam uma imagem ideal de ser feminina. De forma que "a construção de um organismo forte, assentada no trinômio 'saúde, força e beleza', passa a ser meticulosamente observada, visto que a densidade do ser forte é tolerada até o ponto em que não ultrapasse aqueles limites ditados por sua 'natureza', ou ainda pelo que a biologia convencionou designar como sendo próprio do corpo feminino" (GOELLNER, 2004, p.165).

A definição desses limites baseava-se na compreensão naturalizada do que é ser homem e do que é ser mulher, de acordo com as imposições e expectativas sociais. Considerava-se, então, que "a resistência dos braços, a solidez do punho, que tem tanta importância para o homem, tem, para a mulher importância extraordinariamente menor do que o desenvolvimento da bacia. É impossível desconhecer e não seria lícito na educação pôr de lado a constituição ou o sexo e submeter a juventude, como em Esparta, e agora na Escócia, aos mesmos exercícios; e se importa ter o maior cuidado da organização delicada das meninas, (...) não importa menos dar-lhe, por meio de uma educação física adequada, o vigor necessário, para que possam sem perigo suportar a maternidade e sair-se galhardamente das duras provas, que a esperam" (AzEVEDo, 1960, p.82).

Fernando de Azevedo determinava que a "educação física da mulher deve ser, portanto, integral, higiênica e plástica, e, abrangendo com os trabalho manuais os jogos infantis, a ginástica educativa e os esportes, cingir-se exclusivamente aos jogos e esportes menos violentos e de todo em todo compatíveis com a delicadeza do organismo das mães, como sejam entre estes a dança ao ar livre e a natação, a que deve preceder um curso regular de ginástica inteligentemente administrada" (1960, p.82-3).

A dança era a única prática corporal permitida às mulheres no século XIX, sobretudo as danças litúrgicas, que conferiam à bailarina um caráter quase sagrado. Porém, no início do século XX, de acordo com as ideias defendidas por Fernando de Azevedo, ela foi concebida como "um método de educação corporal feminina baseado na assimilação de um código de movimentos tidos como belos, harmoniosos e graciosos, que permitem às mocinhas a expressão - totalmente 'espontânea' de sua 'natureza' feminina” (SCHPun, 1999, p.45). Frequentemente realizada ao ar livre, visando o contato com a natureza e a valorização do seu aspecto higiênico, tratava-se do treinamento dos gestos para assegurar que a espontaneidade não estragasse o efeito desejado, objetivando o "controle absoluto sobre o corpo".

A disseminação da dança clássica, enquanto um "território esportivo exclusivo das mulheres", deveu-se principalmente à repercussão mundial de Isadora Duncan, dançarina que "reverencia a arte grega e recorre à sua estética para celebrar representações de beleza e de feminilidade em seu trabalho" (GOELLNER, 2003, p.133). Em 1916, em turnê pela América Latina, Isadora apresentou-se em São Paulo e encontrou pessoas aptas a aplicar sua arte.

A ginástica feminina, segunda prática apontada por Fernando de Azevedo como adequada às mulheres, foi profundamente influenciada pela dança. Isso porque era necessária a preparação física dos bailarinos, dos quais se exigia flexibilidade, destreza, leveza nos saltos, etc. A maior parte dos dirigentes de escolas de bailado da Europa criou formas de trabalho físico que foram sistematizadas e difundidas em outros países, originando a chamada ginástica feminina.

Sua característica monótona, repetitiva, contrária à espontaneidade e controladora das "tendências corporais e psíquicas", fez com que a ginástica estivesse fortemente assimilada às práticas corporais femininas. "Ela apresenta vantagens significativas como o exercício individual, que não exige utilização de equipamentos especiais nem grandes espaços nem companhia e permite ainda às mulheres que se exercitem em casa, sem se afastar do lar, e que conciliem as obrigações domésticas e forma física” (SCHPun, 1999, p.41). Além disso, a ginástica era valorizada por ser completamente despida de competitividade, agressividade, desejo de vitória, não contribuindo para o desenvolvimento da ambição individual.

Outra prática destacada como fundamental à manutenção da saúde feminina era a caminhada, ou seja, andar a pé ou correr pequenas distâncias, sobretudo no campo. Valorizava-se essa prática pelo aspecto higiênico das saídas ao ar livre e pelo desenvolvimento muscular pouco significativo, já que um simples passeio era considerado suficiente.

A última prática apontada por Fernando de Azevedo é a natação, que se justificava como adequada às mulheres por proporcionar a harmonia plástica do corpo e inspirar a graça dos movimentos. Além disso, era ressaltada nesta prática a necessidade de intuição de ritmo, relacionada ao sexto sentido feminino, e a inconstância do meio líquido, 
que se assemelhava à alma da mulher e por isso as atraía mais do que aos homens (SCHPUN, 1999).

Apesar do nascimento da natação feminina competitiva só ocorrer na década seguinte, foram presenciadas na década de 20 tímidas tentativas de aparições públicas de nadadoras. "Em São Paulo, coube a um pequeno grupo de moças da colônia alemã romper as maiores barreiras antepostas à mulher no desporto pelos costumes e preconceitos locais, ao se apresentar em público para nadar, ainda que envoltas em prodigiosos costumes de banho, abundantes em dobras e babados. As restrições encontradas em casa por estas jovens eram menores, porque elas advinham de uma cultura tradicionalmente adepta aos cuidados com o físico e à apreciação dos encantos da natureza. Além disso, a natação gozava da fama de dispensar a força muscular, portanto, não prejudicando as virtudes femininas de graciosa fragilidade impostas pelo machismo dominador" (LENK, 1982, p.17).

As práticas corporais, além de propiciar a formação de uma juventude bela e forte, apresentavam funçôes de distinção social. Os clubes privados ofereciam às famílias da oligarquia espaços privilegiados para a socialização, servindo de muralhas contra a ascensão social e contra as misturas de classes. Nesses espaços, a participação das mulheres era frequente e revelava-se mais "igualitária" em relação aos homens, uma vez que elas pareciam estar "entre iguais" com seus parceiros esportivos. Através de atividades como o tênis e a equitação, a burguesia local tentava distinguir-se socialmente e identificar-se a seus pares.

A importância atribuída à presença das mulheres nas quadras de tênis devia-se à necessidade que a elite via em participar de atividades de manutenção, de gestão e de acumulação da rede de relações familiares e mundanas. As duplas mistas reforçavam essa imagem de partilha vivenciada de maneira agradável, porque elas ofereciam uma ocasião a mais para se regularizar os sexos. Em todo caso, no nível das sociabilidades e das representações, a participação das mulheres era bem recebida, pois respondia a aspiraçôes comuns do conjunto do grupo (SCHPUN, 1999).

Com a instituição oficial das competições de tênis, que já continham categorias femininas e mistas, dois tipos de reação foram presenciados: enquanto os sucessos esportivos das mulheres como signos de progresso geral eram aplaudidos por uns, para outros provocava um certo incômodo, expresso através de manifestações de misoginia. O segundo comportamento era reforçado pela repercussão da carreira esportiva da tenista francesa Suzanna Lenglen, campeã seis vezes em Wimbledon, cuja força dos movimentos era comparada às "atitudes típicas do jogo másculo", não correspondendo à imagem da graça e da harmonia dos movimentos esperada das mulheres.

Na Sociedade Hípica Paulista, fundada em 1911, apesar de estarem excluídas das atividades realizadas na sede social, as mulheres frequentavam regularmente o centro esportivo e praticavam equitação. "De fato, o hábito de montar é, desde o período rural da oligarquia, dividido com as mulheres por tratar-se de uma prática tradicionalmente familiar" (SCHPUN, 1999, p.56). A hípica, porém, era mais do que um local de prática e competição, pois proporcionava o encontro da elite paulistana. Com seu número de sócios extremamente restrito, eram realizadas competiçóes, que contavam com uma pequena participação de mulheres, e passeios a cavalo, que eram atividades mistas.

\section{As práticas corporais de movimento em clubes de São Paulo}

Os periódicos, em particular, são uma importante fonte para a compreensão da contrariedade dos discursos acerca da presença feminina em atividades físicas. Ora exaltavam as performances das atletas dos clubes e divulgavam imagens das "sportswomen" de outros países, que praticavam modalidades pouco ou nada difundidas entre as mulheres paulistanas como o golfe, o tiro ao alvo, o boxe, o salto fantasia e o motociclismo, ora reafirmavam os propósitos eugenistas e higienistas da Educação Física feminina proposta por Fernando de Azevedo, publicavam piadas que ridicularizavam as mulheres que fugiam aos papéis e/ou padrões estéticos socialmente impostos, além de dedicarem às leitoras colunas que tratavam sobre utensílios para a casa e dicas de beleza.

As modalidades encontradas foram o tênis, o atletismo, a natação, a bola ao cesto, a dança clássica e os jogos presentes em atividades sociais. Para finalidade desse artigo abordaremos apenas o atletismo, a bola ao cesto e os jogos presentes em atividades sociais. Há uma explícita discrepância entre a quantidade de material encontrado sobre cada atividade, o que influiu nas possibilidades e densidade da análise. Também há algumas práticas corporais que embora conste registros fotográficos às vezes com legendas, nada foi escrito sobre elas. Nessas condições, são 
apresentadas a esgrima, a ginástica, o vôlei, o remo e o pólo aquático. A opção pela inclusão dessas atividades, ainda que somente por imagens, parte da compreensão de que os "silêncios", assim como os "discursos", estão repletos de significados.

Embora menos divulgado que o tênis, as mulheres praticavam também o atletismo. Os registros restringem-se a duas menções em edições da Revista Esperia (REVISTA EsPERIA, 1928, 1929).

- nas quais há notas sobre o desenvolvimento do esporte no clube, publicadas na coluna "Indiscriçôes" - e algumas fotos.

A primeira nota trata sobre o grande interesse que os treinos femininos estavam despertando nos frequentadores do clube, o que pode justificar-se pela modalidade ser tradicionalmente uma prática masculina. "Mas as moças que estão em treino pouco se incomodam com os basbaques; visam apenas fortalecer seu physico, e fazer brilhante figura, obtendo bons resultados". Percebe-se o reconhecimento de que há um envolvimento efetivo dessas mulheres com sua prática, condição essencial para que elas apresentassem um bom desempenho e ampliassem suas possibilidades de atuação na modalidade.

Porém, de acordo com a segunda nota, nem todos os espaços apresentavam condições favoráveis ao crescimento do atletismo feminino:

A Federação de Athletismo, com esse negócio de competiçôes femininas, parece que está "tapeando" o pessoal. Marcam a competição para um certo dia, e dahi a pouco, já noticiam a transferencia. Depois, a data é alterada novamente. Eassim pouco a pouco vão desanimando as pequenas que estão treinando. (Revista EsPeria, 1931).

O posicionamento da Federação reforça a ideia de que a discriminação de gênero nos esportes se apresentava de forma cada vez mais velada. Isso porque não se assumia uma posição contrária à presença feminina nas pistas, mas eram elaboradas estratégias para desmobilização das atletas.

Embora os textos não se refiram especificamente às provas do atletismo, por meio das fotos é possível identificar mulheres participando do salto em altura, do arremesso de dardo e do arremesso de peso. $\mathrm{Ou}$ tro aspecto que se destaca nas imagens é o uniforme, composto por uma camisa sem mangas e gola, e um "short". Essa vestimenta destaca-se das que eram utilizadas nas demais práticas corporais por ser extrema-mente apropriada à exercitação física.

Em reportagem publicada na revista "Sports", em 1920, foi realizada uma análise sobre a modalidade esportiva mais adequada às mulheres:

\begin{abstract}
O tennis é, incontestavelmente, um dos sports mais apropriados para a educação physica feminina. Nelle, porém, quando chega a competição entre os dois sexos a vantagem foge sempre para o lado mais forte, isto é, para o homem. Nos sports athleticos essa differença é ainda mais accentuada. (...) $\mathrm{O}$ athletismo é, em resultados, muito mais favoravel aos representantes do sexo feio que nelle encontram robustez e violencia, bem dispensaveis para a mulher. (SPORTS, 1920.)
\end{abstract}

As mulheres lutavam para conquistar seu espaço nas modalidades esportivas com o intuito de exercer seu direito de usufruir as diversas práticas corporais existentes na época, tanto nos espaços de lazer quanto nas competições. Dessa forma, é despropositada a adoção da comparação dos desempenhos de homens e mulheres como critério de adequabilidade de uma modalidade à prática feminina. Além disso, esse critério mostra-se novamente incoerente ao desconsiderar a desigualdade de condiçóes e quantidade de prática. Pois, enquanto as mulheres buscavam superar as barreiras impostas à sua presença, os homens já possuíam um histórico de atuação nas diversas modalidades. Isso se confirma ao observarmos a progressiva diminuição da diferença entre os recordes mundiais femininos e masculinos ao longo do século XX.

No excerto, ainda é criada uma dicotomia entre os gêneros ao utilizarem expressóes como "lado mais forte" e "sexo feio", em contraposição ao "lado mais fraco" e o "sexo belo", para referir-se a homens e mulheres, respectivamente. Essa oposição reforça a ideia da existência de mundos distintos, ou seja, a impossibilidade do compartilhamento de espaços, funçôes, atividades profissionais, práticas corporais etc. Trata-se de uma retomada da ideia de que não existiria realização possível para as mulheres fora da esfera privada, nem para os homens dentro de casa, já que a eles pertencia a vida pública.

Outra modalidade na qual as mulheres estavam presentes era a bola ao cesto, praticada somente no Club Esperia e na Associação Athletica São Paulo. Assim como a disseminação dessa prática, as menções à participação feminina em publicações da época também eram poucas, restringindo-se a duas fotografias da equipe do Esperia e uma reportagem sobre a partida realizada entre os dois clubes.

Os uniformes utilizados para a prática de bola ao cesto apresentam-se de formas bastante distintas nas duas fotos da equipe feminina do Club Esperia. Em uma delas as atletas estão vestidas com saias pelos tornozelos, camisas com mangas compridas e punhos, as golas possuem laços e outros detalhes. Na outra foto, publicada no periódico do clube em 1929, as saias estão 
na altura dos joelhos, as camisas não possuem mangas e as golas não apresentam quaisquer ornamentos. $\mathrm{O}$ desconhecimento da data da primeira foto - encontrada nos arquivos do clube apenas com a especificação "década de 20" - não nos permite inferir, assim como no tênis, sobre uma possível conquista das atletas em relação às vestimentas para a prática esportiva.

A reportagem publicada na Revista Esperia, em 1929, trata sobre o "encontro de bola ao cesto entre turmas femininas", que foi parte do programa de uma Semana de Educação Physica. O texto dessa publicação destaca-se dos demais escritos na época pela utilização de expressões pouco usuais na descrição de jogos em que havia a participação de mulheres.

$\mathrm{O}$ jogo foi disputado com muito ardor, chegando mesmo algumas vezes a assumir phases violentas, dando um trabalho insano ao juiz do encontro. Apesar disso, boas jogadas foram registradas, e bellos lances á cesta resultaram em pontos, dos quaes a nossa turma fez a maior parte, assegurando-se deste modo a victoria das medalhas oferecidas pela Comissão de Educação Physica.

$\mathrm{O}$ relato desse jogo demonstra o intenso envolvimento das atletas com a modalidade e com a competição, o que, somado à rivalidade existente entre as duas equipes, proporcionou um acirramento da partida. Isso contraria a concepção de Fernando de Azevedo, que considerava adequadas às mulheres as atividades desprovidas do sentimento de competitividade. Outro aspecto presente neste excerto é que os elogios tecidos referem-se à dimensão técnica e tática da partida, reconhecendo o valor das jogadoras pelo seu desempenho na modalidade. Também cabe destacar a premiação, que, diferentemente do tênis, congratulou as vencedoras com medalhas.

$\mathrm{O}$ texto da reportagem ainda finaliza parabenizando as atletas e fazendo considerações acerca da participação feminina nos esportes:

Seu exemplo é digno de merecer numerosas imitadoras, que um acanhamento injustificavel afasta das competiçōes esportivas, quando seria de desejar que o esporte feminino fosse desenvolvido parallelamente ao esporte masculino. As pioneiras da educação physica feminina por isso mesmo merecem maiores elogios, porquanto arrostam com os preconceitos, certas de agir bem.

É de grande excepcionalidade para a época um homem manifestar-se publicamente para exaltar o desenvolvimento do esporte feminino com características similares ao masculino. Isso porque poucos consideravam adequado o envolvimento de mulheres em atividades físicas que proporcionassem um esforço intenso, contato corporal e rivalidade consentida. Também é importante destacar que, pelo que foi analisado, não podemos considerar injustificável o "acanhamento" de muitas mulheres, uma vez que eram constantemente elaboradas novas formas de dificultar seu acesso às atividades do mundo público.

Entre essas formas estava a omissão, que pode ser exemplificada pela ausência de espaço que algumas modalidades femininas tinham na mídia da época. Em decorrência disso, há poucos registros da participação de mulheres em alguns esportes, dentre eles a esgrima, a ginástica, o vôlei, pólo aquático e o remo.

$\mathrm{O}$ caráter eugênico da Educação Física feminina, que visava o fortalecimento da Nação por meio do nascimento de crianças saudáveis, estava assentado na compreensão da maternidade como a mais importante missão da mulher, de forma que era necessário o desenvolvimento de exercícios físicos específicos que a preparassem para a reprodução. A partir dessa visão funcional da exercitação física feminina, não haveria espaço e nem sentido para o compartilhamento de práticas corporais entre homens e mulheres. Esse pensamento invalidava as conquistas das atletas que adentravam as diversas modalidades antes restritas à presença masculina.

Ainda haviam eventos sociais promovidos pelos clubes nos quais as atividades físicas eram uma forma de sociabilização da elite paulistana. Dentre eles, destacavam-se os "five-o' clock teas" e os "garden parties" do Paulistano, onde as pessoas se reuniam e jogavam tênis, croqué, diabolô, pingue-pongue, pelota e peteca. Esses encontros também eram valorizados por acreditarem que "os diferentes jogos entre famílias traziam benefícios para a educação física das moças" e ainda que "sem as mulheres, essas atividades se tornariam 'até embrutecedoras" (CLUB ATHLETICO Paulistano, 2000, p.26). Porém, essa atribuição às mulheres da responsabilidade pelo "desembrutecimento" das atividades supõe a delicadeza como uma característica inata à sua condição feminina.

Gentis senhoritas e distintos rapazes, por sua vez, jogavam a peteca, considerada por muitos como nacional e que tem a vantagem de cansar menos. (...) Nas partidas de pingue-pongue, o sexo forte sempre foi derrotado.

No excerto é abordada a adequabilidade da peteca à prática mista por sua reduzida exigência física, o que evidencia a equivocada compreensão de que o corpo feminino não deveria ser submetido a esforços intensos. Também é retomada a expressão "sexo forte" para referir-se ao homem, em oposição à mulher como o "sexo fraco", conforme discutido anteriormente. 
O Club Athletico Paulistano, segundo o relatório anual de 1927, possuía uma piscina que era ponto de reunião diário de inúmeras famílias de associados. Porém a utilização do espaço estava submetida a uma rígida divisão de horários: "Os homens ficavam a 'sós' entre as sete e as oito horas de segunda a sábado. As mulheres tinham a piscina a sua disposição às segundas, quartas e sextas, entre as oito e dez horas, e às terças, quintas e sábados, entre as dez e doze horas" (Club Athletico Paulistano, 2000, p.39). O funcionamento da piscina em regime misto ocorria nos domingos e feriados, e das 14 às 19 horas nos outros dias. No entanto, os relatórios anuais, o periódico e os livros sobre a história do clube não apresentam qualquer justificativa para essa separação de gênero.

As festas ao ar livre do Club EspEria, segundo as fotografias publicadas no periódico do clube sob o

\section{Considerações finais}

É importante ressaltar que os espaços e formas de exercitação física constituem um microcosmo da sociedade, e o que se verifica no campo das práticas corporais é uma intenção de manter as mulheres paulistas dentro dos padrões comportamentais manifestos até então, contendo o movimento que apontava para as conquistas femininas. Há registros de que desde o século XIX algumas mulheres buscavam romper a resistência masculina exercitando-se em lugares públicos, ainda que se constituíssem em manifestações isoladas e por isso eram recriminadas. Ainda assim, no início do século XX há uma intensificação da prática de atividades físicas por mulheres.

Uma das soluções encontradas para a manutenção do controle sobre o corpo feminino nas décadas de 20 e 30 foi limitar as possibilidades de práticas corporais, atribuindo a elas objetivos explicitamente higienistas e eugenistas, inspirado no ideal nazista. Dessa forma, as mulheres não faziam atividades físicas pelo seu direito à prática, pelo exercício de sua cidadania, mas para a construção de uma Nação mais forte, com a qual elas contribuíam tendo filhos saudáveis, ou seja, título "Alguns aspectos da última festa do Club Esperia", também contavam com atividades físicas, nas quais homens e mulheres participavam em provas separadas. As modalidades femininas fotografadas foram a corrida de 100 metros para senhorinhas, o carrinho de mão e a corrida em "saccos". Já os homens competiam no remo, corrida de três e cinco mil metros, corrida de revezamento, corrida em "saccos" e a prova surpresa.

Apesar do material referente à prática de atividades físicas por mulheres ser escasso, fica clara a ausência de um consenso sobre a aceitação feminina. Nas reportagens da época é possível perceber diferentes reaçôes: uns exaltavam, outros criticavam, havia os que silenciavam - por desmerecerem ou pela insegurança do porvir. Isso refletia a instabilidade social gerada pelo avanço das mulheres em diversas áreas - nas artes, na política, no mercado de trabalho, na educação, etc.

exercendo aquilo que os homens consideravam sua principal função, a maternidade.

Consideradas incapazes de governar a si mesmas e aos outros, devendo, portanto, submeter-se à autoridade masculina em casa e fora dela, eram também excluídas do direito ao corpo e ao prazer sexual, sob pena de serem olhadas como anormalidades ou monstruosidades. Desse modo, "a grande conquista feminina e feminista do século XX, também chamado 'século das mulheres', foi o direito à existência, sem o que é impossível começar, se queremos um mundo fundado na justiça social, no respeito e na liberdade" (RaGo, 2004, p.34).

É possível afirmar que as experiências advindas da década de 20 no que se refere tanto às práticas femininas recomendadas, quanto às que eram consideradas inadequadas, foram fundamentais para a ampliação das possibilidades de práticas corporais entre as mulheres brasileiras e também para o exercício da cidadania entre as mulheres. Isso porque esse movimento se constituiu a partir de conquistas em vários âmbitos sociais e o esporte foi mais um deles.

\section{Abstract}

\section{Female corporal practices in paulista clubs in the earlier XX century}

In the decade of 20, sports were still accepted as a male institution, which disabled the female athletic experience, being only the athletics, the classic dance and the basketball (called "bola ao cesto") considered as healthy activities to the so called "fragile gender". Once banned from stadiums and sport 
institutions as well as from the very public life in that time, the female condition was limited by the dedication towards home and family. Notwithstanding, the Feminism strived for the right to citizenship and to a legal existence in public life. The Physical Education very itself referred women as physically active through its discourses within eugenics and hygienic purposes. The aim of this study is to discuss how occurred the women participation in corporal practices in clubs in the decade of 20 in São Paulo city.

UnItERMS: Feminism; Clubs; Sport and women; Decade of 20.

\section{Referências}

AZEVEDO, F. Da educaçáo física: o que ela é, o que tem sido e o que deveria ser, seguido de Antinoüs, estudo da cultura atlética e a evolução do esporte no Brasil. 3.ed. São Paulo: Melhoramentos, 1960.

BRUSCHINI, C. Mulher, casa e família. São Paulo: Vértice, 1990.

ENGEL, M. Psiquiatria e feminilidade. In: PRIORE, M.D. História das mulheres no Brasil. São Paulo: Contexto, 1997. GOELLNER, S.V. Bela, maternal e feminina: imagens da mulher na Revista Educação Physica. Ijuí: Editora Unijuí, 2003. O espetáculo do corpo: mulheres e exercitação física no início do século XX. In: CARVALHO, M.J.S.; ROCHA, C.M.F. (Orgs.). Produzindo gênero. Porto Alegre: Sulina, 2004.

GUARESCHI, N.M.F; MEDEIROS, P.F; BRUSCHI, M.E. Psicologia social e estudos culturais: rompendo fronteiras na produção do conhecimento. In.: GUARESCHI, N.M.F;; BRUSCHI, M.E. (Orgs.). Psicologia social nos estudos culturais. Petrópolis: Vozes, 2003. KOLNES, L.-J. Heterosexuality as an organizing principle in women's sport. International Review for the Sociology of Sport, Munich, v.30, n.1, p.61-77, 1995.

LENK, M. Braçadas e abraços. Rio de Janeiro: Grupo Attântica-Boa Vista, 1982.

LOURO, G.L. Gênero, sexualidade e educação. Petrópolis: Vozes, 1997.

MALUF, M.; MOTT, M.L. Recônditos do mundo feminino. In: SEVCENKO, N. (Org.) História da vida privada no Brasil: República, da Belle Époque à Era do Rádio. São Paulo: Companhia das Letras, 1998.

PINTO, C.R.J. Uma história do feminismo no Brasil. São Paulo: Fundação Perseu Abramo, 2003.

RAGO, M. Trabalho feminino e sexualidade. In: PRIORE, M.D. História das mulheres no Brasil. São Paulo: Contexto, 1997. REVISTA ESPERIA, São Paulo: Clube Esperia, v.1, n.2, out. 1928.

REVISTA ESPERIA, São Paulo: Clube Esperia, v.1, n.10/11, jul./ago. 1929.

REVISTA ESPERIA, São Paulo: Clube Esperia, v 3, n.28, fev. 1931.

REVISTA MENSAL DO CLUB ATHLETICO PAULISTANO, São Paulo: Club Athletico Paulistano, v.1, n.4, dez. 1927. REVISTA MENSAL DO CLUB ATHLETICO PAULISTANO, São Paulo: Club Athletico Paulistano, v.2, n.4, abr. 1928. REVISTA MENSAL DO CLUB ATHLETICO PAULISTANO, São Paulo: Club Athletico Paulistano, v.2, n.9, set. 1928. REVISTA MENSAL DO CLUB ATHLETICO PAULISTANO, São Paulo: Club Athletico Paulistano, v.2, n.11, nov. 1928. SCOTT, J.W. Gender as a useful category of historical analysis. In: PARKER, R.; AGGLETON, P. (Eds.). Culture, society and sexuality: a reader. London: UCL, 1999.

SCHPUN, M.R. Beleza em jogo: cultura física e comportamento em São Paulo nos anos 20. São Paulo: Bontempo, 1999. SOIHET,R. Mulheres pobres eviolência no Brasil urbano. In: PRIORE, M.D. História das mulheres no Brasil. São Paulo: Contexto, 1997. VEIGA-NETO, A. As idades do corpo: (material)idades, (divers)idades, (corporal)idades, (ident)idades.... In: AZEVEDO, J.C. (Org.). Educação e utopia na educação cidadã. Porto Alegre: Ed. UFRGS, 2000.

SPORTS, São Paulo: Sociedade Hípica Paulista, v.1, n.4, mar./abr. 1919.

SPORTS, São Paulo: Sociedade Hípica Paulista, v.1, n.5, jun. 1920.

SPORTS, São Paulo: Sociedade Hípica Paulista, v.2, n.11, maio 1921a.

SPORTS, São Paulo: Sociedade Hípica Paulista, v.2, n.12, jun. 1921 b.

\begin{tabular}{r|l} 
ENDEREÇO & \\
Kátia Rubio & \\
Escola de Educação Física e Esporte - USP & Recebido para publicação: 13/10/2008 \\
Av. Prof. Mello Moraes, 65 & Revisado em: 01/10/2009 \\
05508-030 - São Paulo - SP - BRASIL & Aceito: 02/12/2009 \\
e-mail: katrubio@usp.br &
\end{tabular}
e-mail: katrubio@usp.br 